\title{
A VACINAÇÃO DO HPV E O SINTOMA: APROXIMAÇÕES ENTRE FOUCAULT E A PSICANÁLISE
}

\author{
HPV VACCINATION AND THE SYMPTOM: APPROACHES BETWEEN FOUCAULT AND \\ PSYCHOANALYSIS
}

LA VACUNACIÓN DEL HPV Y EL SÍNTOMA: APROXIMACIONES ENTRE FOUCAULT Y EL
PSICOANÁLISIS

Ana Luisa Lana Pinto Fialho*

Cristina Moreira Marcos*

\begin{abstract}
RESUMO
O texto tem como objetivo promover uma articulação entre a psicanálise e a biopolítica de Foucault, com base em uma pesquisa de mestrado no Programa de Pós-Graduação em Psicologia da PUC Minas. Explora dois eixos norteadores da pesquisa: as políticas públicas de vacinação do HPV no Brasil e a teoria psicanalítica. Três pontos principais direcionam a pesquisa: muitas meninas apresentaram sintomas pós-vacina não esperados: paralisias nas pernas, dificuldades de locomoção, desmaios e desmaios coletivos. Mães criaram comunidades virtuais para se manifestar contra a vacina do HPV, provocando uma reação negativa a esta e levando a uma grande queda na adesão à campanha. $\mathrm{O}$ andamento da pesquisa nos levou a questionar, por meio da análise do discurso das mães, dos materiais oficiais e de produções das mães nos grupos virtuais, a eficácia das campanhas, fazendo uma leitura baseada em Foucault e na psicanálise. O sintoma parece produzir uma falha no ideal da biopolítica.
\end{abstract}

Palavras-chave: Vacinação. Sintoma. Biopoder. Freud. Foucault.

\begin{abstract}
This study aims to establish an interconnection between Foucault's biopolitics and the Psychoanalysis, based on a master degree research inserted in the Psychology Post-Graduate Program at the Pontifical Catholic University of Minas State (PUC Minas). It explores two guiding axes of the research: public HPV vaccination policies in Brazil and psychoanalytic theory. Three main points lead the research: several girls presented unexpected post-
\end{abstract}

\footnotetext{
O artigo foi escrito com base em uma pesquisa de mestrado realizada no Programa de Pós-Graduação em Psicologia da PUC Minas e integrou as discussōes ocorridas durante a pesquisa $O$ que quer uma mãe hoje: um estudo da maternidade no século XXI a partir da psicanálise, financiada pela Fapemig.

*Mestra em Psicologia pela PUC Minas, psicanalista. Endereço: Rua Ceará, 1284, sala 1202 - Funcionários, Belo Horizonte-MG, Brasil. CEP: 30150-311. E-mail: analulana@gmail.com.

**Doutora em Psicanálise pela Universidade de Paris 7, docente do Programa de Pós-Graduação em Psicologia na PUC Minas, psicanalista. Endereço: Rua Bernardo Guimarães, 1209, sala 701 - Funcionários, Belo Horizonte-MG, Brasil. CEP: 30140081. E-mail: cristinammarcos@gmail.com.
} 
vaccine symptoms: paralysis in the legs, difficulties to move around, fainting and collective fainting. Mothers created virtual communities to protest against the HPV vaccine, causing a negative reaction against the vaccine it and leading to a large reduction in the adherence to the campaign. The progress of the research led us to question the effectiveness of the campaigns, through the analysis of the mothers' discourse, the official reports and the mother's statements in the virtual groups developing an overview based on Foucault and psychoanalysis. The symptom seems to cause a failure in the ideal of the biopolitics.

Keywords: Vaccination. Symptom. Biopower. Freud. Foucault.

\section{RESUMEN}

El texto tiene como objetivo promover una articulación entre el psicoanálisis y la biopolítica de Foucault a partir de la investigación de maestría en el Programa de Postgrado en Psicología de la PUC Minas. Explora dos ejes orientadores de la investigación: las políticas públicas de vacunación del VPH en Brasil y la teoría psicoanalítica. Tres puntos principales dirigen la investigación: muchas niñas presentaron síntomas post vacunación no esperados: parálisis en las piernas, dificultades de locomoción, desmayos y desmayos colectivos. Las madres crearon comunidades virtuales para manifestarse contra la vacuna del $\mathrm{VPH}$, provocando una reacción negativa a la misma y llevando a una gran caída en la adhesión a la campaña. El progreso de la investigación nos llevó a cuestionar, a través del análisis del discurso de las madres, de los materiales oficiales y de producciones de las madres en los grupos virtuales, la eficacia de las campañas, haciendo una lectura a partir de Foucault y del psicoanálisis.

Palabras clave: Vacunación. Síntoma. Biopoder. Freud. Foucault.

\section{INTRODUÇÃO}

vacinação contra o papiloma vírus humano (HPV) se tornou uma política $A$ pública no Brasil, entrando para o calendário de imunização em 2014, 1 Lapós estudos e testes de validação da vacina. O principal público-alvo da campanha de vacinação lançada em março de 2014 eram meninas entre 9 e 13 anos. A partir de 2017, a campanha se estendeu para os meninos de 11 a 15 anos e para as meninas de 9 a 15 anos incompletos.

A vacina tem como propósito prevenir quatro tipos principais de câncer de colo de útero, que tem a terceira maior incidência de casos em mulheres no Brasil, ficando atrás somente do câncer de mama e do colorretal. $\mathrm{O}$ tema de nossa dissertação se definiu por indagações surgidas a partir da leitura e da análise de reportagens e artigos de jornais a respeito daquela campanha nacional de vacinação contra o HPV. 
O acompanhamento da campanha pelos diversos tipos de mídias nos despertou interesse pela forma com que se apresentaram as supostas reações à vacina que várias meninas tiveram, no Brasil e em outros países, após a vacinação. Elas apresentaram um tipo peculiar de sintomatologia, a princípio não esperada, após a imunização. Desmaios, perda de sensibilidade nas pernas, dificuldades de locomoção eram os mais destacados.

Impressionou-nos sobremaneira a forma como esses acontecimentos mobilizaram grupos de mães em torno do tema, principalmente nas redes sociais. Foram criadas várias comunidades virtuais a respeito do assunto, como o grupo Sou contra a vacina HPV, que divulga notícias e depoimentos sobre o assunto, em sua maioria questionando a vacina e seus supostos efeitos negativos. Então definimos como nosso objetivo, ao realizar esta pesquisa, investigar o discurso das mães a respeito da vacinação contra o HPV, utilizando como campo de pesquisa conteúdos divulgados na internet como reportagens e grupos no Facebook.

A imprensa potencializou os sintomas acima descritos como consequências da vacina, dando um tom de fracasso à campanha de vacinação. Na mídia televisiva, houve a divulgação de notícias sobre o "caráter irreversível das reações à vacina", desde "convulsões à possibilidade de paraplegia" até a morte de uma criança em outro país. Outros sintomas divulgados sobre aquelas reaçôes foram "começou a ficar sem pernas", "começou a formigar", "um monte de crianças chorando" e "perda de memória, a ponto de não reconhecer os pais".

Foram divulgados, nas redes sociais, os casos da cidade de Bertioga, São Paulo, e da cidade de Carmen del Bolivar, na Colômbia, nas quais esses sintomas acometeram, de maneira coletiva, meninas, mobilizando hospitais e autoridades de saúde a se pronunciarem sobre o assunto (Bitencourt, 2014; Formenti, 2014; Jahaísa, 2014; "Fantástico:Meninas", 2014). Em todos os casos citados, os serviços de vigilância epidemiológica em saúde dos municípios asseguraram que tais manifestações não têm probabilidade de ser uma reação própria ou comum à vacina.

A sintomatologia apresentada interessou-nos pelo forte conteúdo psíquico manifestado, e nos perguntamos: seriam essas reações uma histeria após a vacina? As mães se tornaram porta-voz das meninas vacinadas e interpretaram, a seu modo, a "reação" das filhas: "amoleceu feito gelatina" (Formenti, 2014). Tais comentários maternos nos levaram a indagar o que estaria em jogo, de um lado, para as meninas vacinadas e, de outro, para as mães que autorizaram a vacinação.

Observamos também que, na segunda etapa da campanha de vacinação, em 2014, houve uma grande queda na procura pela vacina. Nas escolas, foram distribuídos formulários a serem preenchidos pelos pais antes da vacinação (o 
"Termo de Recusa de Vacinação contra HPV"), que deveria ser preenchido caso não concordassem com a vacinação. Em Belo Horizonte, as estatísticas da campanha nas escolas indicaram uma adesão, na primeira etapa, de $86 \%$ de meninas vacinadas. Já na segunda etapa, esse número caiu para 22\%. No Brasil, de acordo com dados do Portal do Ministério da Saúde, a queda foi de 99\% para 57\%. Esses dados nos levam a perguntar: o que causou tal queda? O que se passou com as meninas e suas mães para que não completassem as etapas da vacinação?

Considerando a faixa etária das meninas-alvo da vacina, 9 a 13 anos, indagamos se não haveria, tanto para as meninas que respondem sintomaticamente à vacinação quanto para suas mães, um confronto com questões relativas à sexualidade que as fazem recuar. Poderia a vacinação criar, no imaginário das mães, a ideia de que a vida sexual da filha terá início devido à significação de conteúdo sexual que acompanha a vacina?

$\mathrm{Na}$ mídia escrita, diante da divulgação daquelas reações, os órgãos oficiais do governo no Brasil garantiram a confiabilidade da vacina. "Não houve registro de eventos adversos graves em mais de 4 milhões de vacinas aplicadas em todo o Brasil na primeira etapa, de acordo com as sociedades médicas" (Estado de Minas, 2014). Contudo as medidas de incremento da campanha de vacinação pareceram insuficientes para alcançar os resultados esperados.

Em torno desse ponto giram questões cruciais desta pesquisa: poderiam essas reações se referir a uma sintomatologia histérica, tal como a compreende a psicanálise? A oposição à vacinação poderia indicar uma recusa de um encontro com o real do sexo, já que a vacina remete, em alguma medida, à sexualidade? A vacina contra HPV estaria antecipando questôes da sexualidade de meninas para elas e para as mães? O despertar da sexualidade, coincidente para as meninas com momento da vacinação contra o HPV, poderia ser impedimento para a adesão à vacina?

\section{A VACINAÇÃO CONTRA O HPV: COMO ELA SE TORNA UMA POLÍTICA PÚBLICA?}

A partir da Lei no 12.401, de 28 de abril de 2011, que dispóe sobre a assistência terapêutica e a incorporação de tecnologias em saúde no âmbito do SUS, foi estabelecida, no Brasil, a campanha nacional de vacinação contra o HPV. A nova lei estabelece a exigência do registro prévio do produto na Agência Nacional de Vigilância Sanitária (Anvisa) para que este possa ser avaliado para a incorporação no SUS. Para regulamentar a composição, as competências e o funcionamento da Conitec foi publicado o Decreto $n^{\circ}$ 7.646, de 21 de dezembro de 2011. 
Essa vacina contra o HPV foi disponibilizada no Brasil à população por meio da campanha nacional de vacinação do Ministério da Saúde, lançada em 2013 e iniciada em março de 2014. O esquema de vacinação ocorre em duas doses e é oferecido a cada ano, no intervalo de seis meses após a primeira dose. Então, as campanhas de vacinação ocorrem, pelo menos, duas vezes ao ano.

O "Guia prático sobre o HPV", um documento do Ministério da Saúde (Brasil, 2014), traz informações importantes sobre a vacinação. A incorporação da vacina HPV no calendário nacional de vacinação do adolescente representa, segundo esse documento, uma estratégia de saúde pública para reforçar as atuais ações de prevenção do câncer do colo do útero. Ela é ofertada gratuitamente nas unidades básicas de saúde e em escolas públicas e privadas. A campanha ocorre de forma gradativa: em 2014, a população-alvo da vacinação foi composta por adolescentes do sexo feminino na faixa etária de 11 a 13 anos. Em 2015, foram vacinadas as adolescentes do sexo feminino, na faixa etária de 9 a 11 anos. A partir de 2016, a idade mudou para a partir de 9 anos de idade.

O esquema de vacinação escolhido é recomendado pelo Grupo Técnico Assessor de Imunizações da Organização Pan-Americana de Saúde (TAG/ OPAS), após aprovação pelo Comitê Técnico Assessor de Imunizações (CTAI) do Programa Nacional de Imunizaçōes (PNI). O esquema estendido já foi adotado por países como Canadá (Québec e Colúmbia Britânica), México, Colômbia e Suíça. Essa faixa etária foi escolhida como público-alvo da vacinação na rede pública, tendo em vista que a vacina é altamente eficaz nas meninas de 9 a 13 anos não expostas ao vírus, de preferência antes do início da vida sexual. Portanto, para que a estratégia de vacinação seja efetiva, é necessário focar a vacinação nesse grupo, a fim de se atingirem as metas preconizadas.

A meta da vacinação nessa primeira campanha foi alcançar $80 \%$ do públicoalvo. A vacinação foi restrita ao sexo feminino, pois o objetivo dessa estratégia é reduzir casos e mortes ocasionados pelo câncer de colo uterino. Estudos comprovam que os meninos passam a ser protegidos indiretamente com a vacinação no grupo feminino (imunidade coletiva ou de rebanho).

Quanto à segurança e efeitos colaterais, o guia explicita: a vacina contra HPV é muito segura, desenvolvida por engenharia genética, com a ocorrência de eventos adversos leves, como dor no local da aplicação, inchaço e eritema. Em raros casos, pode ocasionar dor de cabeça, febre de $38^{\circ} \mathrm{C}$ ou mais e síncope (ou desmaios). A síncope mais frequente em adolescentes e adultos jovens é a síncope vasovagal, particularmente comum em pessoas com alguma particularidade emocional. Geralmente há algum estímulo desencadeante, como dor intensa, expectativa de dor ou um choque emocional súbito. 
Entre os fatores que podem aumentar a probabilidade da ocorrência desse sintoma está o "medo de injeção", além de jejum prolongado, permanência em locais quentes ou superlotados, permanência de pé por longo tempo e fadiga.

Ainda é preciso dizer que o Ministério da Saúde estabeleceu a faixa etária de 9 a 13 anos para a vacinação porque, nas meninas dessa idade não expostas aos tipos de HPV 6, 11, 16 e 18, a vacina é altamente eficaz, induzindo a produção de anticorpos em quantidade dez vezes maior do que a encontrada em infecção naturalmente adquirida em um prazo de dois anos.

A estratégia adotada pelo Ministério da Saúde para sensibilizar os pais sobre a importância de vacinar suas filhas contra o HPV foi a produção de materiais educativos para os pais ou responsáveis, adolescentes e profissionais de saúde e educação, esclarecendo os objetivos da vacinação e a sua relevância como medida de saúde pública para a redução da morbimortalidade do câncer do colo do útero.

Campanhas massivas na televisão, cartazes, mídia em geral, redes sociais e grupos de jovens foram, ainda, estratégias usadas para sensibilização. Houve vacinação nas escolas públicas e privadas. Ainda, foram realizadas orientações quanto à necessidade de continuidade do rastreamento da doença e à prevenção das demais doenças sexualmente transmissíveis.

Os profissionais de saúde, técnicos e professores nas escolas foram preparados para abordar o tema com pais de adolescentes e com os próprios adolescentes, por meio de mídias sociais, pelos meios de comunicação tradicionais, como campanhas de massa, distribuição de materiais educativos e manuais voltados aos diferentes públicos, como professores, adolescentes, pais e responsáveis, profissionais da saúde e população em geral.

O material da campanha de vacinação do Ministério da Saúde nos ajuda a verificar as estratégias empregadas para atingir a população-alvo, ou seja, as meninas, evidenciando um apelo ao coletivo de meninas para a vacinação.

\section{A BIOPOLÍTICA E A QUESTÃO DA SEGURANÇA DA VACINA: O EXEMPLO DA VACINAÇÃO CONTRA A VARÍOLA NO SÉC. XVIII}

Em seu texto Aula de 25 de janeiro de 1978, do livro Segurança, território e população, Foucault (2008) cita a vacinação contra a varíola no século XVIII como dispositivo de segurança em saúde e suscita para nós, na Contemporaneidade, o debate sobre prevenção e promoção da saúde. A abordagem foucaultiana contribui para avanços na maneira de tratar a saúde. A noção de segurança 
possibilita uma mudança de abordagem, da doença reinante para as noções de caso, risco e perigo, conceitos que possibilitam, segundo ele mesmo, integrar, no interior de um campo coletivo, os fenômenos individuais. Permite maior controle dos modos de vida, buscando a promoção da saúde.

Assim, buscamos as bases teóricas para chegar a uma resposta a respeito de como os aspectos subjetivos interferem nos números da campanha. Pensamos ser possível, por esta abordagem, provocar algumas questóes a respeito da efetividade da campanha de vacinação do HPV. Colocam-se algumas perguntas: por que uma campanha de vacinação pública, no nosso caso, a da vacinação contra o HPV, apresenta baixa adesão às etapas necessárias para a conclusão do esquema completo de vacinação? O que não garante uma cobertura satisfatória quando toda uma mobilização para a campanha já havia sido feita? Como os fatores subjetivos que atravessam a vacinação podem interferir no resultado final? Como os conceitos de segurança em saúde e biopolítica nos ajudariam nesta pesquisa?

No texto, Foucault (2008) pretende "mostrar o que pode haver de específico, de particular, de diferente nos dispositivos de segurança” (p. 73), comparados aos mecanismos de disciplina que ele havia procurado descobrir nos anos precedentes. $\mathrm{O}$ autor pretende, então, "insistir na oposição, na distinção segurança x disciplina” (Foucault, 2008, p. 73). A questão da normalização é tratada, segundo ele, de maneira diferente pela segurança e pela disciplina. Para Foucault, as técnicas de normalização se desenvolvem na contramão da lei.

A disciplina normaliza e há uma especificidade na normalização disciplinar. Primeiro, a disciplina analisa, decompõe os indivíduos, os lugares, os tempos, os gestos, os atos, as operações. Em segundo lugar, a disciplina classifica os elementos identificados conforme objetivos determinados. Em terceiro lugar, estabelece as sequências ou as coordenações ótimas. Em quarto lugar, estabelece os procedimentos de adestramento progressivo e de controle permanente e, a partir daí, faz a demarcação entre o normal e o anormal. Na normalização disciplinar, é normal quem é capaz de se conformar a uma norma, e o anormal é quem não é capaz. Trata-se muito mais de uma "normação" do que de uma normalização.

Como se normaliza? Para tentar explicar, Foucault usa o exemplo da epidemia, após ter trabalhado em outros textos sobre os exemplos da cidade e da escassez alimentar. Em particular, vai tratar da varíola, uma doença que, em primeiro lugar, foi endêmico-epidêmica no século XVIII. Em segundo lugar, tratava-se da doença mais endêmica de todas da época e de mortalidade elevadíssima. Tinha surtos epidêmicos muito fortes e intensos. Em terceiro lugar, a varíola é um exemplo privilegiado, já que, a partir de 1720, com a variolização, e de 1800, com 
a vacinação, têm-se à disposição técnicas que apresentam quatro características insólitas na prática médica da época: primeiro, de serem absolutamente preventivas; segundo, de apresentarem um caráter de certeza, de sucesso quase total; terceiro, de poderem ser generalizáveis à população inteira e, em quarto lugar, de serem completamente estranhas a toda e qualquer teoria médica. Segundo Foucault, a prática da variolização e da vacinação eram impensáveis nos termos da racionalidade médica da época.

Em termos de efeitos na "polícia médica", a variolização e a vacinação se beneficiaram de alguns fatores que as inscreveram nas práticas reais de população e de governo da Europa ocidental: a possibilidade de generalização permitia pensar o fenômeno em termos de cálculo e probabilidades graças à estatística. Depois, elas se integravam aos outros mecanismos de segurança já citados.

De maneira notável, a variolização não procurava impedir a varíola e sim provocar algo que era a própria varíola, mas em condições tais que a anulação podia se produzir no momento da vacinação. Essa não resultava numa doença total e completa, mas por meio dessa pequena doença inoculada, podiam-se prevenir os outros eventuais ataques da doença.

Esse mecanismo de segurança se assemelha ao da escassez alimentar, citada anteriormente por Foucault. Ele se integra no interior das diferentes tecnologias de segurança e da racionalização do acaso e das probabilidades. Era isso que tornavam aceitáveis essas novas técnicas, se não para o pensamento médico, pelo menos para os médicos, para os administradores, para os que eram encarregados da "polícia médica" e, finalmente, para as próprias pessoas.

Por essa perspectiva, a doença deixa de ter a noção de "doença reinante", conceito predominante até o século XVIII, e passa a ter a característica de caso, devido às análises quantitativas de vários tipos que se tornaram possíveis. A noção de caso aparece não como caso individual, mas como a noção de se poder integrar, no interior de um campo coletivo, os fenômenos individuais.

A partir daí, torna-se possível ter uma noção de risco, desde se pegar a doença até de se morrer dela ou de se curar. A terceira noção desenvolvida é a de perigo. Pode-se identificar o que é perigoso a partir do momento em que se verifica que o risco não é o mesmo para todos os indivíduos, idades, condições, lugares e meios.

O texto de Foucault avança, trazendo as discussões sobre biopoder e soberania, as quais nos possibilitam fazer um paralelo a respeito da mudança de foco ao se passar do sistema disciplinar, que tratava a doença no doente, para o sistema 
de segurança. Em Foucault, o biopoder foi um elemento indispensável para o desenvolvimento do capitalismo. Serviu para assegurar a inserção controlada dos corpos no aparato produtivo e para ajustar os fenômenos da população aos processos econômicos (Castro, 2016).

A biopolítica é um conceito importante nesse contexto. É a maneira pela qual, a partir do século XVIII, buscou-se racionalizar os problemas colocados para a prática governamental pelos fenômenos próprios de um conjunto de viventes como população: saúde, higiene, natalidade, longevidade, raça. A biopolítica estuda fenômenos de massa, em série e de longa duração. Seus mecanismos são os de previsão, de estimativa estatística, medidas globais. A biopolítica persegue o equilíbrio da população, sua homeostase, sua regulação (Castro, 2016).

Em tese, a abordagem da segurança dá embasamento à implantação de mecanismos e programas como os de promoção da saúde, baseados no risco da doença, voltados para a prevenção e acompanhamento de doenças como o tabagismo, o alcoolismo, o controle do uso de benzodiazepínicos, as campanhas de vacinação. Essas práticas trazem maior controle dos modos de vida, priorizando as práticas de autocuidado para o horizonte da promoção da saúde. No entanto as práticas de segurança se baseiam nos cálculos, e sabemos que, em termos de saúde, nem tudo é calculado. Políticas como a estratégia da saúde da família trazem uma perspectiva nova, fazendo uma abordagem maior no território, com análises menos classificatórias.

Ferreira Neto (2013) faz essa discussão no livro Psicologia, políticas públicas e o SUS. O autor traz contribuições importantes para refletir em que medida a institucionalização das políticas sociais de saúde têm reverberado na revisão dos processos de atuação, formação e produção de conhecimento em Psicologia. Tendo Michel Foucault como interlocutor privilegiado, o autor se situa na contramão das corporações disciplinares e da estagnação do pensamento em conceitos (Beato, 2014). Ao acompanhar o pensamento de Foucault, exercita o princípio analítico de abandonar binarismos na forma de entender a realidade. Sem perder de vista o conjunto da obra de Foucault, o autor leva à construção desse pensamento sobre uma gama variada de tecnologias de si, as quais remetem às "práticas psicológicas".

Machado (2017) localiza bem que o conceito de biopoder, que vai além da noção de disciplina, é bem diferente das tecnologias disciplinares; que atuam para formar e transformar o indivíduo pelo controle do tempo, do espaço, da atividade e pela utilização de instrumentos como a de vigilância e o exame.

A psicanálise, por sua vez, se interessa por analisar políticas públicas como a vacinação de meninas pela incidência traumática que a vacinação, ou o apelo a ela, pode ter em jovens adolescentes. O sintoma toma o corpo, entre o vazio e o excesso 
(Laurent, 2016), apontando as nuances da vivência adolescente nos encontros e desencontros com a sexualidade e na contramão do que represente algo de muito universal e generalizante. $\mathrm{O}$ sintoma faz furo por onde se manifesta. No caso das meninas, verificamos esse fato com toda a sua contundência. $\mathrm{O}$ sintoma faz falar o singular de cada sujeito, fazendo furo no universal da política. Os aspectos subjetivos parecem interferir nos números da campanha e na efetividade desta. $\mathrm{O}$ sintoma histérico, apresentado pelas meninas, "descompleta" uma programação anteriormente feita com estratégias de divulgação, treinamento e envolvimento dos profissionais e sensibilização dos pais para a vacina, que resulta em fracasso. Se o biopoder vai além do controle, a psicanálise vai além, ao trazer à tona o sintoma e a subjetividade.

\section{SOBRE O SINTOMA DAS MENINAS}

Alguns casos divulgados pela imprensa no Brasil e no exterior ilustram bem os sintomas manifestados pelas meninas. Revelam também um aspecto importante: o acontecimento coletivo desses sintomas, que acometeram várias meninas ao mesmo tempo.

Após apresentarem reação à segunda dose da vacina contra o HPV, 2 das 11 adolescentes atendidas no Hospital Municipal de Bertioga, no litoral de São Paulo, voltaram a ser internadas na unidade (Bitencourt, 2014; Fantástico: Meninas..., 2014; Formenti, 2014). Elas apresentavam sintomas parecidos e não conseguiam andar porque não sentiam o movimento das pernas. Acompanhadas pelas mães, as adolescentes Luana e Mariana, de 12 e 13 anos, precisaram retornar ao hospital. As duas haviam sido atendidas anteriormente e liberadas, mas voltaram a apresentar os mesmos sinais que tiveram após a aplicação da vacina e ficaram internadas. Segundo a mãe de Luana, a filha começou a passar mal dois dias antes do atendimento, cerca de uma hora depois de ter tomado a vacina no colégio. Ela, Mariana e as outras meninas que apresentaram os sintomas estudam na mesma escola. No mesmo dia, Luana foi medicada e teve alta. No entanto os sintomas persistiram no dia seguinte. "Eu estava no trabalho e me ligaram da escola, dizendo que a Luana estava passando mal de novo. Aí eu fiquei preocupada", relata Rosália. Mais uma vez, a menina foi medicada e liberada, mas quando chegou em casa, passou mal pela terceira vez. "Ela estava deitada no sofá e, de repente, começou a tremedeira, a dor de cabeça e a tontura. E da cintura para baixo, ela paralisou”, diz a mãe.

Com Mariana, a reação se deu de forma parecida. De acordo com a mãe da adolescente, a filha tomou a vacina no mesmo dia que Luana e também começou a passar mal em seguida. "Foi na saída da escola. Ela estava indo para 
casa acompanhada de uma colega, quando teve a tremedeira na rua e desmaiou. Uma viatura da ronda escolar passava na hora, e a outra menina pediu socorro. Aí trouxeram a Mariana para o hospital", lembra a mãe.

A menina também foi medicada e liberada no mesmo dia, mas voltou a passar mal. Na terceira vez que procurou o hospital, ficou internada. "A Mariana já teve reação quando tomou a primeira dose da vacina. Ela desmaiou e teve dor de cabeça, mas não sentiu nada nas pernas. Agora, ela não consegue andar”, descreve Fabíola.

Fabíola acrescenta que a preocupação das mães é que as filhas tenham complicações por causa da reação à vacina. "Elas começam a passar mal, e a gente não sabe o que vai acontecer. A gente fica com medo do estado de saúde delas se complicar, e elas ficarem com sequelas", finaliza.

Em nota, a Prefeitura de Bertioga informou que as reações estavam sendo investigadas e que a orientação da Secretaria Estadual da Saúde era de não suspender a aplicação da vacina (Bitencourt, 2014).

Os efeitos pós-vacina parecem ser colocados em um patamar dramático que expõe bem a situação de temor vivida pelas mães, que indagam às outras se vão arriscar a vida de suas filhas e consideram que o governo brincou de roleta russa com suas filhas. Isso demonstra o clima de incerteza e insegurança presente entre as mães quanto à vacinação após a divulgação das supostas reações à vacina.

\section{SINTOMA, HISTERIA E IDENTIFICAÇÃO}

Como as reações apresentadas pelas meninas à vacina (paralisias nas pernas, formigamentos, dificuldades de locomoção, desmaios e desmaios coletivos) não faziam parte do conjunto de sintomas esperados à vacinação, perguntamos: haveria a possibilidade de elas se configurarem como sintomas histéricos? Tratar-se-ia de um processo de identificação histérica como descrito por Freud? Quanto às mães, estariam elas influenciadas pelo excesso de notícias e imagens que "viralizaram" nas redes sociais? Poderíamos pensar em uma característica epidêmica desses numerosos casos descritos pela mídia?

Segundo André (1986), na conversão histérica, o conflito entre o orgânico e o sexual, entre a necessidade e o desejo se resolve na invasão completa da função orgânica pela função sexual. Na formação do sintoma, a necessidade é apagada pelo impulso do desejo que se apossa do órgão, que se torna puramente genital, desprovido ao máximo de sua função sensória. A pulsão sexual passa de mista a pura no sentido em que, em vez de se apoiar no somático, apossa-se dele e o anula. É também o que acontece na alternância entre bulimia e anorexia, em que 
ora é a função orgânica da boca, ora é sua função erótica que assume a direção. Não comer aparece para sustentar o nada do desejo. Prosseguindo, André (1986) nos mostra que, por outro lado, entre a função real do corpo e a função simbólica que este adquire por efeito do recalque, vem se inserir uma função imaginária cuja prevalência na histeria Freud observa.

Freud notou, desde os Estudos sobre a histeria (Breuer \& Freud, 1893), que, mesmo quando a queixa da histérica parece apontar para um órgão ou um local interno ao corpo, é sempre a uma geografia imaginária do corpo que ela refere sua dor, sua contração ou paralisia. A inserção de uma função imaginária da imagem corporal entre o processo significante do recalque e o real do organismo assume muita importância na clínica da histeria e nas questões da feminilidade em geral. A histérica nunca se sente o bastante revestida por essa imagem corporal, como se essa vestimenta imaginária ameaçasse sempre se entreabrir para a realidade repulsiva de um corpo que ela não pode reconhecer como tal.

Para Freud, os sintomas têm um sentido e se relacionam com as experiências do paciente. Freud descobre que, na histérica, o sintoma aparece por somatizações e pode ser interpretável. Suas interpretações remetem aos conteúdos sexuais dos sintomas. $\mathrm{Na}$ conferência $\mathrm{O}$ caminho para a formação dos sintomas, Freud destaca que estes são atos prejudiciais, dos quais o sujeito "se queixa como sendo indesejados e causadores de desprazer ou sofrimento" (Freud, 1917/1989, p. 419) ${ }^{1}$. O principal dano que causam reside no dispêndio mental que acarretam e no dispêndio adicional necessário para se lutar contra eles. Quando há extensa formação desses dois tipos de sintomas, "pode resultar no empobrecimento mental e, com isso, na paralisação da pessoa para todas as tarefas importantes da vida" (Freud, 1989, p. 419).

Os sintomas neuróticos são resultado de um conflito que surge em virtude de um novo método de satisfazer a libido. O sintoma formado é resultado da reconciliação de duas forças em conflito. É resistente, por estar apoiado nas duas forças. Um dos componentes do conflito é a libido insatisfeita repelida pela realidade, que deve procurar outras vias para satisfazer-se. Uma das saídas para a libido será tomar o caminho da regressão, pela fixação que deixou em pontos específicos de seu desenvolvimento.

Segundo André (1986, p. 110), “quando o sintoma é a conversão, há uma prevalência imaginária na histeria”, trazendo a paralisia no corpo. Ainda segundo ele,

1 A primeira data indica o ano de publicação original da obra e a segunda data indica a edição consultada pelo autor; que só será pontuada na primeira citação da obra no texto. Nas seguintes será registrada apenas a data de publicação original. 
A lógica da construção histérica comportaria três etapas: uma falta a nível da imagem corporal i(a) [...] Que deixa aparecer o real do corpo dessexualizado (a) [...] Que a simbolização histérica do sintoma (conversão ou sonho) tenta reparar invadindo o imaginário (André, 1986, p. 110).

O encontro com a sexualidade confronta as meninas vacinadas com o real. Encontramos, nos casos dessas "meninas”, associaçôes importantes à identificação histérica das meninas do pensionato no capítulo VII do texto Psicologia de massas e análise do eu, de Freud (1921/2013), já que a vacinação nos casos da escola em Bertioga traz uma "reação em cadeia”. A identificação é descrita como “a manifestação mais precoce de uma ligação emocional com outra pessoa" (Freud, 2013, p. 93). Ele discorre sobre três tipos principais de identificação formadoras de sintoma, que Lacan apontará como identificações freudianas.

A identificação histérica, na qual há um “apoio do desejo sobre o desejo do Outro" (Millot et al., 1986), corresponde ao terceiro tipo. Essa identificação se efetua sobre a base de um desejo comum, de uma "mesma disposição afetiva", sem que a pessoa a quem a histérica se identifica seja necessariamente o objeto de um investimento libidinal. Ela se efetua frequentemente pelo sintoma. $\mathrm{O}$ sujeito histérico se apropria do sintoma de um outro no ponto em que esse sintoma expressa essa comunidade de relação com o desejo. Lacan, citado por Millot et al. (1986), mostra que, por esse tipo de identificação, o sujeito se constitui como desejo do Outro. "A histérica não pode fazer outra coisa que buscar o desejo do Outro ali onde este deixa seu vestígio (ou sinal) no Outro" (Millot et al., 1986, p. 126).

Costa (2017) interroga: o que teriam essas meninas para ter o "mesmo" ataque histérico? Seria possível encontrar uma proposta universal (alguma coisa que pudesse ser comum a todos) na histeria? Buscando a resposta em Freud, seria aquilo que ele propôs como modelo de identificação histérica: a identificação ao sintoma. O que é comum na histeria toca, então, em um ponto de desfalecimento, pelo qual o ataque histérico se torna uma caricatura e produz esse compartilhamento, esse "como se fosse um". Algo do falso aparece aí, e Freud o chama de imitação.

Nas notas do Seminário les non-dupes errent, de Lacan, Costa (2017) localiza uma citação que complementa Freud: "Este é todo o trabalho da organização, da organização imaginária, se podemos dizer: simular [...] - e sempre temos de lidar com isso para daí recolher um grupo - simular com a multidão algo que funcione como um corpo".

A equiparação do grupo a um corpo ou a vertente da simulação no lugar do corpo remete, para a autora, a algo bastante presente na sintomatização histérica: a condição de tomar para si qualquer discurso sobre o corpo e, principalmente, 
sobre um corpo que não funciona. Assim, ela considera o grupo "funcionando como um corpo na organização da comunidade e do indivíduo" (Costa, 2017). É aí que localizamos os fenômenos dos desmaios, dos desfalecimentos das meninas vacinadas, várias, centenas ao mesmo tempo. As reaçóes à vacina vão ganhando um contorno epidêmico a partir do terceiro tipo de identificação descrito por Freud. A identificação histérica toma o sintoma como instrumento. É o que acontece com as meninas que desmaiam.

\section{CONSIDERAÇÕEES FINAIS}

A campanha da vacinação do HPV se encontra entre as campanhas que tiveram baixo índice de adesão no Brasil. As mães abasteceram as redes sociais, criando e participando de grupos contrários à vacinação do HPV, os quais são muito acessados. A vacinação do HPV não é uma campanha de vacinação como as outras. Ela envolve especificidades que se referem, em primeiro lugar, aos aspectos ligados à sexualidade. Ocorre em um momento delicado da vida das meninas, que é a adolescência. Além do encontro com o real do sexo, movidas pelas pulsões sexuais, elas se deparam com a separação dolorosa dos pais que a idade impõe. Estes, principalmente as mães, não querem que suas filhas cresçam. Pode ocorrer que prefiram mantê-las na posição sintomática de objetos, a serviço daquelas. A vacinação das filhas atinge as mães e as coloca às voltas com a sua própria sexualidade, provocando uma turbulência em torno do vacinar ou não.

As manifestações corporais apresentadas pelas meninas, como desmaios e paralisias, apresentam-se como sintomas histéricos. Isso se comprova pela própria teoria de Freud, na qual os componentes psíquicos dos sintomas vão se revelando mediante sua prática. O caminho da formação dos sintomas revela também a força de conteúdos sexuais que tentam ser afastados e se transformam em sintomas. $\mathrm{O}$ aparecimento dos desmaios e paralisias em grupo destacam a força da sintomatologia histérica por meio da identificação.

As mídias sociais, ao divulgarem com bastante destaque esses fenômenos, exacerbam o temor das mães à vacinação. Seus protestos ganham visibilidade entre a população e aparecem como causa da baixa adesão à vacinação entre meninas (Fialho, 2016). Essa baixa adesão não levaria a uma ameaça à segurança da vacina?

As campanhas de vacinação podem ser questionadas dentro de um contexto em que as políticas de controle dos corpos homogeneízam as condutas de prevenção e divulgação, e não consideram a dimensão dada pela psicanálise ao sintoma como expressão singular do sujeito. A dimensão do sintoma traz um ponto de novidade, uma manifestação que não era esperada. Diante dos casos 
de desmaios, paralisias e do conteúdo sexual associado à vacina, as mães recuam. Não respondem, então, ao apelo da campanha de vacinação: "Todas devem se vacinar". O sintoma faz furo, desmontando a garantia de adesão à vacinação, apesar de toda a preparação anterior para esta.

Em O avesso da biopolítica, Laurent (2016) discute como a biopolítica submete o corpo a golpes de imagem e de slogans. Este, no entanto, sempre escapa às identificações prontas para revesti-lo. A psicanálise acolhe esse corpo tomado pelo gozo e pelo trauma. O autor mostra como, na psicanálise, parte-se de um sintoma que faz sofrer, buscando-se reduzi-lo por meio de seu sentido, sua história, a fim de que possa escrever-se de outro modo. Busca-se alojar o gozo que incide no corpo falante, restando ao sujeito suportar o corpo que tem, apoiando-se na escrita de seu sintoma para fazer valer sua presença entre os discursos estabelecidos.

Nossa pesquisa aponta que cada momento da implantação das políticas públicas de saúde sofre influências diversas e a cada fase cabem aspectos positivos e negativos de análise. Consideramos que o nosso tema de investigação indaga esses aspectos a respeito da vacinação do HPV. A interlocução com a psicanálise, com base na teoria do sintoma, traz alguns contrapontos. A subjetividade se contrapõe ao coletivo mediante os sintomas apresentados pelas meninas. Eles apontam para a especificidade do momento da adolescência: a reedição edípica dessa fase coloca em destaque os aspectos pulsionais da vivência do corpo, que pulsa com intensidade e força. A questão do tornar-se mulher e a relação específica vivida com as mães também traz desafios que situam uma realidade singular para cada uma dessas meninas. Assim, a característica de universal da política de vacinação é atravessada pelo que o sintoma traz de subjetivo, interferindo na efetiva cobertura dessa política. 


\section{REFERÊNCIAS}

André, S. (1986). O que quer uma mulher? D. D. Estrada (Trad.). Rio de Janeiro: Jorge Zahar.

Beato, M. S. F. (2014). Política pública como campo na formação, atuação e produção de conhecimento em Psicologia. Estudos de Psicologia, 31(4), 605607. Recuperado a partir de http://www.scielo.br/scielo.php?script=sci_ arttext\&pid=S0103166X2014000400014

Bitencourt, J. (2014, 6 setembro). Jovens ficam sem o movimento das pernas após vacina: "Paralisou". G1, Santos. Recuperado a partir de http://g1.globo. $\mathrm{com} / \mathrm{sp} /$ santos-regiao/noticia/2014/09/jovens-ficam-sem-o-movimento-daspernas-apos-vacina-paralisou.html_

Brasil. Ministério da Saúde. Secretaria de Vigilância em Saúde. Departamento de Vigilância das Doenças Sexualmente Transmissíveis. (2014, fevereiro). Guia prático sobre o HPV: guia de perguntas e respostas para profissionais de saúde. Brasília: Ministério da Saúde. Recuperado a partir de http://portalarquivos2. saude.gov.br/images/pdf/2014/marco/07/guia-perguntas-repostas-MS-HPVprofissionais-saude2.pdf

Breuer, J. \& Freud, S. (1893). Estudos sobre histeria. In J. Salomão (Trad.), Edição standard brasileira das obras psicológicas completas de Sigmund Freud (Vol. 2, pp. 15-297). Rio de Janeiro: Imago, 1989. (Publicado originalmente em 1893).

Castro, E. (2016). Vocabulário de Foucault. Belo Horizonte: Autêntica.

Costa, A. (2017). O tempo da histeria: considerações sobre o coletivo e o sujeito do inconsciente. Falando Nisso, 18. Recuperado a partir de https://www.unijui. edu.br/arquivos/clinicapsicologia/informativos/falandonisso18/ensaio.pdf

Decreto no 7.646, de 21 de dezembro de 2011. (2011, 21 dezembro). Dispóe sobre a Comissão Nacional de Incorporação de Tecnologias no Sistema Único de Saúde e sobre o processo administrativo para incorporação, exclusão e alteração de tecnologias em saúde pelo Sistema Único de Saúde - SUS, e dá outras providências. Diário Oficial da União, Brasília.

Ferreira Neto, J. L. (2013). Psicologia, políticas públicas e o SUS. São Paulo: Escuta; Belo Horizonte: Fapemig.

Fialho, A. L. L. P. (2016). HPV: "Histeria pós-vacina?”. Transfinitos, 15, 315322. 
Formenti, L. (2014,8 setembro). Vacinação contra HPV não será suspensa. UOL Notícias: Ciência e Saúde. Recuperado a partir de http://noticias.uol. com.br/saude/ultimasnoticias/estado/2014/09/08/vacinacao-contra-hpv-naosera-suspensa-diz-secretario.htm.

Foucault, M. (2008). Aula de 25 de janeiro de 1978. In M. Focault, Segurança, território e população. (pp. 73-166). São Paulo: Martins Fontes, 2008.

Freud, S. (1917). Os caminhos da formação dos sintomas. In J. Salomão (Trad.), Edição standard brasileira das obras psicológicas completas de Sigmund Freud (Vol. 16, pp. 419-440). Rio de Janeiro: Imago, 1989. (Publicado originalmente em 1917).

Freud, S. (1921). Psicologia de massas e análise do eu. (pp. 33-166). Porto Alegre: L\&PM, 2013. (Publicado originalmente em 1921).

Jahaísa. (2014, 21 setembro). Colômbia: vacina contra HPV responsabilizada por doença misteriosa. (2014, 21 setembro). [S.1.]: Notícias naturais. Recuperado a partir de http://www.noticiasnaturais.com/2014/09/colombia-vacina-contrahpv-responsabilizada-por-doenca-misteriosa

Laurent, É. (2016). O avesso da biopolítica. Rio de Janeiro: Contra Capa.

Lei $\mathrm{n}^{\circ}$ 12.401, de 28 de abril de 2011. (2011, 20 abril). Altera a Lei no 8.080, de 19 de setembro de 1990, para dispor sobre a assistência terapêutica e a incorporação de tecnologia em saúde no âmbito do Sistema Único de Saúde SUS. Diário Oficial da União, Brasília.

Machado, R. (2017). Impressôes de Michel Foucault. São Paulo: N1.

Fantástico: meninas começam a receber vacina HPV. (2014, 14 setembro). [S.l.]: Globoplay. Recupelado a partir de https://globoplay.globo.com/v/3217164/

Millot, C., Blancard, M. H., Broca, R., Godin, J. G., Hamon, M. C., Léres, G., . . \&. Vaças, P. (1986). Deseo y goce en la histérica. In Fundación del Campo Freudiano. Histeria y obsesión. (pp. 126-130). Buenos Aires: Manantial. 